\title{
The Digital Divide, Financial Exclusion and Mobile Phone Technology: Two Problems, One Solution? ${ }^{1}$ \\ Neal Geach ${ }^{2}$ N.P.Geach@herts.ac.uk \\ University of Hertfordshire
}

\begin{abstract}
:
The recent growth in the use of electronic communications throughout the world has not included everyone. The vast majority of the world's population is still unable to gain access to digital technology, especially the Internet, hence the 'digital divide'. However, this divide is not restricted to the developing world; with the divide also prevalent within the UK, again particularly in terms of internet access. A result of this situation is that while the UK and many of its citizens reap the benefits that the Internet brings, areas are left even deeper in a state of financial exclusion from mainstream banking facilities. As more people take advantage of the convenience the Internet can bring to managing financial affairs, the banking industry has identified a need for less branches and staff. From their understandable perspective it makes more sense to close unprofitable, high risk branches. These are ultimately in rural or poor inner city areas; the areas that are less likely to have Internet access. Advances in mobile phone technology could prove a solution to both.
\end{abstract}

\section{Introduction}

The issues of 'Digital Divide' and 'Financial exclusion' are far from being recent phenomena yet both continue to persist. Mobile phones have often been seen as a possible solution to the former, particularly in developing countries for whom the debate on the issue tends to focus. While this focus is perhaps justifiable due to the acuteness of the problem in the developing world, the issue also needs addressing within the UK. A lot of focus has been given to the latter issue in the UK with various political and economic proposals suggested but none have proved to be a full success. This paper examines the extent of the UK's digital divide and its correlation to financial exclusion. The potential of mobile phone technology, particularly recent developments in Kenya, will be assessed to see whether that technology could be the solution to not only bridging the digital divide but also bringing people back into the financial mainstream. This paper ends by linking in with the EU review of electronic communications regulatory framework to ensure that sufficient security measures are in place for this proposal to have the consumer confidence that is needed for it to work.

\section{The Extent of the UK Digital Divide}

The search for a specific definition as to 'Digital Divide' has been described as "somewhat complex" but the problem for which it encompasses is the gap between those with access to information and communication technologies (ICT) and those without. In 2006 the International Telecoms Union (ITU) together with the United Nations Conference on Trade and Development (UNCTAD) launched the Digital Opportunity Index ${ }^{4}$ (the Index). The aim of which is to provide a means of measuring the digital divide and the progress in closing it. The Index takes 11 internationally agreed ICT indicators and places them into three categories namely, opportunity, infrastructure and 
utilisation. The indicators used by the Index centre on telephony and the Internet; both mobile and fixed in each instance. The Index ranks the UK $12^{\text {th }}$ out of 40 nations studied, with an overall score of 0.60 , where 1 equals the highest value. Interestingly, the UK's score for the specific category of opportunity is $0.96\left(9^{\text {th }}\right.$ overall $)$. This category deals with the affordability of ICT services and the geographic coverage of those services. Overall this would suggest that the UK does not have a digital divide and that its citizens have very good opportunities to access ICT services. This is important as having the opportunity to access ICT is widely acknowledged to bring a range of benefits, both economic and social. For example, the Organisation for Economic Co-operation and Development has established a link between Internet access and improved educational performance ${ }^{5}$ However, the Index is weighted towards telephony in the opportunity category with only a third of the marking weighted towards Internet access. This would support the basis for focusing on Internet connectivity when debating the digital divide. This is evidenced by an independent study conducted by BT on the subject who chose to define 'digital exclusion' as "not having access to the Internet at home"6. The question to be considered therefore is whether, taking the narrower context of Internet access, such a divide exists within the UK.

According to the Office of National Statistics (ONS) for the period January to April $200657 \%$ of households within the Great Britain had access to the Internet ${ }^{7}$. This figure then fluctuates depending on the precise area surveyed. For the same period the figure for the South East is 66\%, while Scotland only had Internet access in $48 \%$ of households. These to areas represent the highest and lowest areas of Great Britain in respect of Internet access. A historical look at the figures also highlights that there has been an ongoing trend for certain pockets of the Britain to be outperforming certain others. While London and the South East have always had the highest number of households with Internet access, areas such as the Scotland and North East England have traditionally being among the lowest ${ }^{8}$.

The suggestion of a digital divide is reinforced when the social make up of Internet users in taken into account. In the 2001 - 2002 National Statistics Omnibus Survey ${ }^{9}$ highlighted the fact access to the Internet also depends on the gross income of households. The bottom income domicile ${ }^{10}$ of households based on gross income, only $11 \%$ had Internet access, the highest $10 \%$ had $80 \%$ access; with the level of access increase as the gross income of households increased. This is further supported by statistics supplied by the charity Citizens Online. Their survey of Internet use by social class $^{11}$ shows that in 2005 the group DE, usage was just over $30 \%$. Social class AB's usage was just under $80 \%$. It is significant that the lower social classes will have the lower gross incomes and although not exclusively, they will certainly be represented in those regional areas with low Internet access scores in the 2006 figures.

It appears clear therefore that a digital divide exists within the UK, arguably two $^{12}$. This is of particular concern when as Gonzalez has noted ${ }^{13}$ that there is "as strong link between economic wealth and internet access within a population", perhaps due to the overall strength of the UK economy and of its citizens the economic impact on those that have been left behind by the take up of internet access has been overlooked. The double blow for this sector of society is that the Internet is having an ever increasing impact on the way people can partake economically in society. Therefore, it is important 
to assess the economic impact the Internet in relation to the provision of financial services within the UK.

\section{The Impact on Financial Services}

Financial exclusion is broadly referred to as not having access to "mainstream financial products such as bank accounts and low costs loans."14 The foreword to the Treasury's report 'Promoting Financial Inclusion' (The Report) states “financial exclusion imposes real costs on individuals and their families ........It also has costs for the communities in which they live" 15 . Individually, the costs include higher fees for basic transactions such as transferring money and cashing cheques, inability to pay bills by direct debit which can leads to surcharges being applied to those bills, and also barriers to employment as a bank account is a basic requirement for a number of jobs ${ }^{16}$. For society as a whole, financial exclusion can contribute to child poverty ${ }^{17}$, interact and exacerbate social exclusion $^{18}$; there are also economic implications for the country as a whole through benefit payments for those who cannot gain employment or through loss of taxation from those who have to resort to the black economy. As of 2003 one in twelve households, or 2.8 million adults did not have access to a bank account ${ }^{19}$.

Therefore, there is without question a financial divide as well in the UK, but where is this divide and is there a correlation with the digital divide described above? The answer appears to be a clear yes. As noted above the lowest income domicile had the lowest access to the internet, the Family Research Survey for 2002 -2003 indicates over $25 \%$ of households within this income domicile did not have a bank account. This figure progressively declines, with the top domicile having a figure of less than $5 \%$. The correlation is supported by further figures within The Report; although it acknowledges the difficulty in obtaining precise information about geographical location, it suggests that those who are financially excluded are concentrated in certain areas. Scotland and the North East are two areas that have significant concentrations of financially excluded households, as with Internet access.

Undoubtedly there is an element of cause and an effect involved with these figures, the question being the extent that one divide is the cause of the other. Arguably the stronger suggestion is that low income areas suffering from financial deprivation are not likely to outlay on something that may not seem necessary in Internet access. However, the issue of cost was provided for as a separate response in the aforementioned Citizens Online survey in the previous section, and in fact was given as a reason on fewer occasions than lack of connection. Additionally, events in the financial services industry lend weight to the suggestion that lack of Internet access is at least fuelling, if not causing, financial exclusion. This is particularly so when financial exclusion is considered in the broader context of having an actual bank account but not having access to it, in addition to not having any bank account.

The Internet has brought many benefits in the provision of financial services. One can do their personal banking in the comfort of their home with no queues, nor time restrictions; in fact e-banking.co.uk reported at the end of last year that $86 \%$ of Internet users found online banking "simpler than visiting their branch" 20 . Industry figures also demonstrate the rapid growth in online banking use. Over the period $2004-2005$ there was a $27 \%$ increase in customers using online services ${ }^{21}$. However, these convenience 
has come at a cost at least some customers. In 2005 Clydesdale Bank announced the closure of 47 branches. The reason given for this action by Clydesdale's chief operating officer, David Thorburn, was the need to make the bank more competitive and efficient ${ }^{22}$. The justification for using branch closures as a method of achieving this was that the bank having surveyed its customers found that $72 \%$ did not use their branch at all while only $11 \%$ used the branch once ${ }^{23}$; more customers were using the Internet instead. This scenario of bank closures unfortunately has been common throughout the industry over recent years. The impact in the Clydesdale Bank instance is particularly significant in light of the previous discussions within this article; of the 47 branches closed 17 were in England while 30 were in Scotland. Of these 8 closures meant that those communities no longer had any banking facilities ${ }^{24}$. Naturally, banks are not going to close busy and profitable branches. This would suggests that when the decision comes to close branches it will be those within either low income deprived areas or remote rural ones; the areas less likely to have Internet access.

Those within these communities who do have accounts but no longer any branch only have the use of automatic teller machines (ATM) to obtain their money. As of June 2006, the UK's network of ATMs stood at 58,750. ${ }^{25}$ Of these 25,500 (43\%) were fee charging $\mathrm{ATM}^{26}$ and the report notes that most of these are deployed in areas where there is no other ATM. For this reason, where these fee charging ATM are located is important. Unfortunately, the locations are similar to those identified earlier in relation to Internet access and financial exclusion with large concentrations in parts of Scotland, the North East and Merseyside.

Therefore, it appears there are two distinct but related divides within the UK which are in important need of rectification. However, it is suggested a proven solution to both issues already exists and could be implemented in the UK effectively at low cost and little governmental involvement.

\section{M-pesa - bridging the divide?}

It is fair to say that there is some substance to the view Kenya is not part of the developed world. Although there has been sustained economic growth in recent years, of a population of just under 35 million $50 \%$ live in poverty. The country's infrastructure

remains severely underdeveloped. For example there is only $8,993 \mathrm{~km}$ of paved roads and $2,778 \mathrm{~km}$ of railway ${ }^{27}$. Fixed telephone lines amount to a total of $303,905^{28}$. However, against this backdrop there have been extremely impressive developments within the mobile phone sector. For the period July $1^{\text {st }} 2005$ to June $30^{\text {th }} 2006$ mobile subscribers rose $40.6 \%$ to a total of $6,648,791^{29}$; while coverage is $80 \%$ coverage of the country ${ }^{30}$. More significantly, is the recent launch of M-pesa ${ }^{31}$ by mobile phone operator Safaricom ${ }^{32}$; the objective of which is "to improve the efficiency of Microfinance by using mobile technology to make transactions faster, cheaper, and more secure" 33 . It is important to note that M-Pesa is no longer merely a trial but a fully operational service available to phone users that has already proved successful ${ }^{34}$. The technology has been around for some time in South Korea. In June 2004 alone, some 581,000 Koreans were making 4 million banking transactions ${ }^{35}$. However, Kenya is clearly different to South Korea and what the Kenyan service highlights is that provided the will is in place, mobile coverage to provide the service can be achieved in even the remotest of areas ${ }^{36}$; and the 
service can bring significant benefits to people living in poverty with no access to banking facilities.

\subsection{The functionality of the service}

Essentially M-pesa is a financial services program within a mobile phone. Users of the service need a new generation SIM card that has the software embedded into it. This provides one of the first benefits of the system. If you are already a mobile phone user but which to take advantage of M-pesa, you only need to go to your local dealer to upgrade your SIM card. This reduces the cost implications as if the software was handset specific, such as with the Vodafone live! Service, you would need to buy a new phone. What then, are the financial services that M-pesa allows to be performed on a mobile phone? Firstly four types of money transfer are provided, these are:

(1) person to person (P2P)

(2) individual to business

(3) cash withdrawals at a registered outlet

(4) receipt or payment of loans

all of which are executed by SMS text message. Additional features are the ability to see balances in real time and order statements.

The transfer facility works in very much the same way as PayPal on the Internet. A user must have an account with Safaricom in which to pay cash into initially ${ }^{37}$. The user then simply selects the option that they want, for example 'Send Cash' and enters the phone number for the individual or business that they wish to receive the funds. The amount is then entered followed by the user's PIN. A confirmation screen then appears; by selecting 'OK' an SMS will be sent to M-pesa. The user will then receive an SMS from M-pesa confirming that the funds have been sent, and a code for the recipient to use. The recipient will also receive an SMS stating they have been sent funds from the user. To be able to physically obtained these funds the recipient must go to the nearest registered outlet with the code that the user sends separately and directly to the individual to withdraw the funds from their account. The transfer is instantaneous, meaning there is immediate access to funds removing the delay that is seen in the normal clearing process.

\subsection{The benefits}

What makes the system particularly attractive for implementing in the UK is that while the registered outlet could be a bank it alternatively could be a mobile phone retailer or just a local shop, eliminating the issue of banks moving out of certain areas. The key benefit is therefore, that no access to a bank is needed by either party; all that is needed is traditional cash to pay into a Safaricom account ${ }^{38}$ by the person wishing to send the funds. This means that the technology could have a significant impact for two sectors of UK society namely, those who live in areas where no traditional financial institution is located and there is no ability to use Internet banking, and those who do not even have a bank account, as they can have funds text to them. The M-pesa technology is therefore, a viable alternative to the traditional financial system. Basic everyday banking deposit and withdrawal services can be done and goods can be purchased. The latter is of particular interest to those who while able to get a bank account, have to make do with 
the most basic form, generally called a cash card account. This type of account while allowing the holder to withdraw funds from an ATM does not allow card payments to be made in shops. Therefore, if the account holder requires certain goods for which they do not have sufficient cash on them, and no cash machine is nearby, the holder would currently have to go without.

However, having access to these facilities is all very well but if the costs involved mean that the user is priced out of taking advantage of the facility then the system losses its attraction as a means of bringing people into the financial mainstream. Again, M-pesa provides advantages over traditional financial services. As previously noted a key concern currently within the UK, is a lack of free to use ATMs particularly in deprived or low income areas. In some instances the ATM will not be one connected to a 'high street bank' but part of the Link system or Travelex. These ATMs in order to generate profits for the operator charge fees for withdrawing money, commonly around $£ 1.50$. Obviously in areas where this is the only ATM the result is that constant use by individuals to obtain money will have a detrimental impact on their overall level of available funds. With Mpesa, the charge for withdrawing money is only $\$ 0.50$. Although, as M-pesa allows individuals to send funds via SMS, potentially people do not even need to withdraw funds. While there is still a charge for the transfer facility it is only $\$ 0.25$ to a registered number and $\$ 0.50$ to unregistered numbers.

There are also benefits for businesses who take advantage of the service. Generally when a person pays on a credit card a percentage is retain by the card payment authorisation body APACS. No such charge is retained under M-pesa, the result being that it is ideal for low value payments; in Kenya it is even used for paying for taxis. Additionally, as noted above the potential customer base for a business is increased by providing a means of payment and an access to funds that for some people currently do not exist. This has the potential therefore, to help maintain and increase trade in local shops, which in turn contributes to the local economy and community as a whole by ensuring they remain going concerns.

A further cost benefit is evidenced by a price comparison for bank transfers in the UK. A same day transfer from an account with one bank to another with a different bank, such as Barclays to Halifax, would leave the sender with a payable fee in the region of $£ 20.00$. Obviously, there are ways of transferring funds without suffering charges but this is when the bank clearing system becomes an issue. Firstly, there is the BACS transfer method; while free it takes up to three working days for the funds to clear. Alternatively, one could send a cheque however; this takes even longer to clear and is more open to fraud. Ultimately, the main issue is that they all require access to a bank. Arguably a cheque does not as they can be cashed by a cheque cashing service but these institutions charge commission. This means if it was a low income worker's wages they would have even less money. Under M-pesa for a fee of no more than $\$ 0.50$ a user will have the ability to send, receive and get access to the funds instantaneously.

A final benefit applies to people who wish to send money overseas; in particular migrant workers, many of whom have come to this country to benefit from higher wages. Money is then sent back to their native country for the benefit of family members. However, when these funds are transferred overseas there is potentially a charge by the recipient's bank as well as the sender's ${ }^{39}$. Consequently, the total sum sent per transaction is diminished. Additionally, the regularity of transactions may be reduced to 
avoid the charges. However, as mobile phone usage is growing significantly in the developing world, the technology behind M-pesa has the potential to drastically reduce the costs involved giving the potential to increase significantly the sums of money put into those economies. Vodafone see the service as a catalyst for social and economic growth in these countries. Mastercard have in fact, just announced with 19 mobile phone operator trade body, the GSM Association a pilot scheme to allow this type of transfer to occur at significantly reduced rates. The initiative hopes to double the number of recipients of these international remittances and quadruple the size of the market to $£ 513$ bn by $2012^{40}$. Therefore, while the exact fees have not been stated as yet for international money transfers; as one of the aims of the operators looking at mobile phone technology to transfer funds is to expand into the international remittance market the cost is highly likely to be at reduced levels. This is then obviously beneficial to migrant workers within the UK.

Clearly the main rafts of benefits are in terms of cost, and cost will also dictate whether it the service would be successfully used by those for whom its implementation should be aimed at. It is questionable whether comparable levels of fees would be implemented in the UK for domestic transfers of any type. One of the main aims of Mpesa was to provide banking facilities for those in areas where there is small scale financial infrastructure and to help increase growth in the economy ${ }^{41}$; and the nature of the market dictated prices would need to be low. While these principles are applicable to financially excluded areas of the UK, the banking industry is far stronger. At a time when their other means of generating revenue such as overdraft charges, late payment fees and payment protection insurance are under close scrutiny and being forcibly reduced by the competition authorities; it is likely the banking industry may attempt to resist the technology and/or the low level prices. If this were to occur this lobbying should be resisted by the government and the regulatory authorities as the imposition of high charges for the facilities that M-pesa provides would defeat the object of its introduction $^{42}$. This may lead to charges of government interference in the market place but these concerns are surely outweighed by the public policy benefits to be had by bringing wider access to financial services to those sectors of society that the service should be aimed at.

With these benefits in mind it is appropriate to see whether an equivalent to Mpesa can be applied to those cut off from the financial mainstream within the UK.

\section{Application in the UK}

While M-pesa is specifically a financial service delivered through mobile phones, the sophistication of modern handsets available means that mobile phones also have the added benefit of providing equivalent benefits to the Internet and actual access to it themselves. With the additional benefits of lower costs and less required infrastructure, mobile phones have repeatedly been seen as the best way to close the digital divide ${ }^{43}$. In terms whether M-pesa technology could be used to reduce the second divide of financial exclusion in the UK, three key issues need to be addressed. Firstly, is the infrastructure present (i.e. the mobile phone masts to give reception and the actual mobile phones), in 
the relevant areas for the service to positively impact on the level of financial exclusion within areas of the UK. Secondly, are there sufficient security measures in the current telecommunications regulatory framework to ensure consumer protection and thus ensure take up through confidence in the system?

\subsection{The current infrastructure}

Of the issues highlighted, arguably the most important is that of infrastructure. This requires firstly, that there is sufficient network coverage for mobile phones to operate throughout the UK, particularly in remote rural areas that suffer from a lack of bank branches and Internet accessibility. Secondly, that the population within those regions and social groups suffering from the digital divide and financial exclusion has mobile phones already or can obtain affordable ones. If this is not the case, the targeted benefits of M-pesa would be lost. Its introduction would only serve as an additional method of banking alongside the Internet and traditional phone options.

With regard to the former, the Index ${ }^{44}$ states $^{45}$ as of 2003 , the percentage of the UK population covered by mobile telephony is $99 \%$. This would indicate that the vast majority of potential beneficiaries would not lose out by not being able to use a mobile phone. As for the latter requirement, the Index states that the UK has 89 mobile phone subscriptions per 100 inhabitants. While this figure is high, as the Index notes, this figure should be treated with some caution due to the fact it can include prepaid users who have become inactive, as operators vary the length of time required before a subscriber becomes inactive. Additionally, some people may have more than one phone, for example one for work and one for personal use. Although the 2006 Policy Evaluation by the UK telecommunications regulator Of( $\operatorname{com}^{46}$ puts the number of UK households with a mobile phone at around $80 \%$, with $1 \%$ of people likely to next one in the next 12 months. Significantly, only $2 \%$ of people, across all social demographics, wanted a mobile phone but could not obtain one. Why no reasons are given it is highly likely this percentage consists of people suffering financial exclusion. It is contented that in this instance government aid could be used in order to provide basic handsets that are capable of using the M-pesa technology. Overall however, it would seem that there is sufficient infrastructure for the service to be introduced to the UK and benefit those currently suffering from financial exclusion.

\subsection{Will the existing regulatory framework be sufficient to provide consumer confidence?}

There are two regulatory issues that impact on the potential for the M-pesa technology to be implemented in the UK. The first concerns how the service would itself be regulated due to its financial nature. Would such a service need regulating in the same way as a bank? What would be the precise legal nature of any transactions undertaken? The issue of what regulatory regime would govern the service is important as too harsh a regime may deter operators from offering the service. Due to the similarities between M-pesa and PayPal, it is suggested that the service is more akin to an electronic payment instrument ${ }^{47}$. However, with the EU's Payment Services Directive still to be finalised 
this side of the regulatory position is far from certain. Of arguably more concern from a consumer perspective is how secure the technology is. Regardless of how well regulated something is and strictly defined in law, people will not buy in to such a service if they do not think it will be safe to use. For this reason, this article concentrates on the overall regulatory regime for electronic communications networks and services; specifically the security provisions imposed on operators to ensure their network integrity. If these are not sufficient changes may be required to ensure uptake by consumers.

Security becomes an issue in two instances. The mobile itself could be stolen, potentially allowing the thief to transfer or withdraw funds. The other instance is where the phone is hacked into, akin to that done with PCs. In terms of stolen phones the built in PIN and authentication provisions of M-pesa should mean that provided these details are not held with the phone the thief should not have the opportunity to use the phone for this purpose. Extra security could come from CCTV at the registered outlets for withdrawing any funds and obviously there is the ability to freeze the phone account upon notification that the phone has been stolen. Preventing hackers would appear the more pressing priority ${ }^{48}$. Article 4(1) of the European Directive 2002/58/EC (Privacy and electronic communications) (the E-Privacy Directive), provides that mobile phone operators "must take appropriate technical and organisational measures to safeguard security of its services". These measures must "ensure a level of security appropriate to the risk presented. Having regard to the state of the art and the cost of implementation"49. Further in the case of a particular risk of a security breach they must inform their subscribers concerning the risk ${ }^{50}$. These are not particularly stringent and leave much of the responsibility on the network operators.

Unfortunately, research by The Tower Group states many emerging mobile services "lack a reasonable and justifiable focus" on security ${ }^{51}$. Their research also goes on to highlight that since mobile phones have been able to support PC like applications, more than 200 mobile phone viruses have been identified; with the number doubling every six months. This appears to indicate that operators are not implementing security measures 'appropriate to the risk', which could be because of cost or a lack of awareness of the problem. All of which creates a level of concern about M-pesa's application $n$ the UK and potential problems for getting people who could benefit to use the service.

A solution may be provided by the European Commission's review of the regulatory framework for electronic communications (The Review) of which the ePrivacy Directive is a part. The proposals include clarifying the 'appropriate technical and organisational measures' operators of networks and services must undertake, although no exact clarification has as yet been proposed. Further measures intended to force operators to strengthen their security measures is to give the regulatory authorities such as Ofcom, the power to require information on security policies, require audits and the ability to fine companies for not complying. These reforms still leave a lot of discretion to mobile operators as to what security they provide. Perhaps in the short term at least, bearing in mind the purpose of introducing such a service in the UK and the demographic of people that purpose is intended for, the M-pesa enabled phones could be restricted to those without PC like applications, meaning the majority of old $2^{\text {nd }}$ generation mobile phones. As the software is embedded on the SIM card there is no need for Bluetooth, or web browser applications in order to download the service; this has the benefit of removing the ability of hacking into the mobile phone. As the service becomes 
more widespread with more people wishing to use it, there will undoubtedly be a customer demand for the service to be on more hi-tech phones. When this comes it is hoped the technology behind the service would have evolved in much the same way as online banking services have to become more sophisticated and resistant to security risks.

\section{Conclusion}

The UK is divided both digitally, in terms of household access to the Internet and financially, in terms of those without access to financial services. While at first glance, they are two separate problems, there is a correlation between the areas that suffer from both and arguably a significant interrelation between them. While mobile phones have, for some time been seen as a way of circumventing problems of internet connectivity and increasing access; it appears mobile phones can also bridge the societal divide caused by financial exclusion.

The technology works and the UK has the required infrastructure to implement the technology. There is a question of could it work in a more advanced economic society with arguably the higher regulatory controls that this brings. Again the evidence would appear that it can, as currently in Japan and South Korea the technology is full use and does not appear to have encountered any operational issues. Obviously, the UK has a different regulatory regime which will bring issues to be addressed as to the legal nature of the transfers but it is suggested the application of the technology would not be hindered by this on the basis of the success of PayPal.

An embryonic mobile banking service has in fact been launched in Britain albeit on a far smaller scale than M-pesa in Kenya. So far the service is limited to checking balances and receiving statements ${ }^{52}$. Nonetheless the biggest obstacle to a full mobile banking service along the lines of M-pesa would primarily be one of cost; which will be impacted on by how it is implemented. If the service is introduced into the UK market merely as a means of providing an ancillary service to sit alongside traditional phone and online banking, then the emphasis on low costs and social development as seen in Kenya may not be prevalent and the benefits potentially will be negated. A paradox that arises is that one way of keeping down costs is to have widespread take up. This would firstly reduce the cost of the required SIM cards by creating economies of scale allowing the software to be produced on mass. However, this requires the service to also be targeted at those already financially included. This as stated potentially increases the likelihood of higher costs.

As a result the government should seek to induce the operators to introduce such a system and ensure that the introduction is primarily for the benefit of the financially excluded. Ultimately, the ideal of one mobile phone being the solution for both divides may be more realistically achieved in the medium term. Technological advances and increased competition in time should result in lower costs and higher handset security. This will allow the incorporation of both Internet and financial applications onto the one handset without any dangers of negating the benefits that could be brought by such a move.

\footnotetext{
${ }^{1}$ Presented at the BILETA Conference 2007, University of Hertfordshire April $17^{\text {th }} 2007$.
} 
${ }^{2}$ The author would like to thank Kevin Rogers and Stuart Weinstein for their help with this work however; all mistakes are solely those of the author's.

3 'The Digital Divide revisited: The Grand Canyon of the online environment', Kevin Rogers, Presented at Cyberspace 2006, Masaryk University Brno.

${ }^{4}$ The 2006 Index is available at www.itu.int/osg/spu/statistics/DOI/index.phtml

${ }^{5}$ Reported in The Observer newspaper 10/12/2006.

6 The Digital Divide in 2025' An independent study conducted by BT 2004, available at http://www.groupbt.com/Societyandenvironment/PDF/Digitaldivide2025.pdf

${ }^{7}$ National Statistics Omnibus Survey 2006, available at

http://www.statistics.gov.uk/CCI/nugget.asp?ID=8\&Pos=\&ColRank=1\&Rank=374

${ }^{8}$ The 2002 Omnibus survey shows only 32\% of households in the North East England and 36\% in Scotland had Internet access compared to $48 \%$ in South East. Available at

www.statistics.gov.uk/pdfdir/intacc0702.pdf

${ }^{9}$ Available at ibid.

${ }^{10}$ Each income domicile is $10 \%$ of the population's households based on gross income.

${ }^{11}$ Available at www.citizensonline.org/statistics

${ }^{12}$ By region and by social class/gross income.

13 'The Digital Divide: It's the Content, Stupid', Part 1 Gonzalez, A G, Computer and Telecommunications Law Review (2005), Volume 11, Issue 3.

14 'Promoting Financial Inclusion A Report' December 2004. Available at www.hmtreasury.gov.uk/media/8F9/37/pbr04_profininccomplete_394.pdf

15 Ibid.

${ }^{16}$ Ibid.

${ }^{17}$ Child Poverty Review, HM Treasury July 2004 available at www.hmtreasury.gov.uk/media/985/CC/childpoverty_complete_290704.pdf

18 'Bringing Britain Together: A Strategy for neighbourhood renewal', Social Exclusion Unit September 1998

${ }^{19}$ The Family Resources Survey 2002 - 2003 available at www.dwp.gov.uk/asd/frs/2002_03/pdfonly/frs_2002_03_report.pdf

20 'Online banking makes life simpler. Study shows' 01/12/2006 available at www.e-banking .co.uk/news/2006/Dec/online-banking-makes-life-simpler,-study-shows.html

21 'growing trend of online banking' 05/04/2005 available www.e-banking.co.uk/news/Apr/2005/growingtrend-of-online-banking.html

${ }^{22}$ Reported by BBC News 'Union condemns closure of banks', 03/11/2005 available at

http://news.bbc.co.uk/go/pr/fr/-/1/hi/scotland/4400018.stm

${ }^{23}$ Ibid.

${ }^{24}$ Ibid.

25 'Cash machines - Meeting consumer needs' ATM Working Group (HM Treasury) 13/12/2006 available at www.hm-treasury.gov.uk/media/727/4C/atm_working group_final.pdf

${ }^{26}$ Ibid, the Report envisages this figure is likely to increase in the short to medium term.

${ }^{27}$ Reported in the CIA Government Fact Book available at www.cia.gov/cia/publications/factbook/geos/ke.html

${ }^{28}$ 2005/2006 Annual Report by the Kenyan Central Bank available at

www.centralbank.go.ke/downloads/publications/annual/annual_2006.pdf

${ }^{29}$ Ibid.

${ }^{30}$ Reported by Paul Mason for Newsnight 'From Matutu to the Masai by mobile' available at http://news.bbc.co.uk/1/hi/technology/6241603.stm

${ }^{31}$ This is the widely used name for the service although it is short for Mteja-Pesa.

$3240 \%$ owned by Vodafone.

33 'Mobile financial services for the third world: Kenyan Pilot', Susan Lonie 29/03/2006 available at http://www.chyp.com/PubWebFiles/DigMoney/9_2006/presentations/susie_lonie.pdf

${ }_{35}$ A trial was carried out throughout last year which involved some 1000 people using the service

35 Reported by Moon Ihlwan for Business Week 27/09/2004 available at http://www.keepmedia.com/pubs/BusinessWeek/2004/09/27/584447/?extID=10047\&data=mobile_banking \&gclid=CNrNzre_i4oCFQS_Xgod0gpRdw 
${ }^{36}$ Even in the Great Rift Valley there is mobile phone coverage.

${ }^{37}$ This is done through any registered outlet.

${ }^{38}$ This is the area where M-pesa differs from PayPal which requires users to have a bank account or credit card to transfer funds to their PayPal account and to obtain the funds on withdrawal from the PayPal account. Arguably, M-pesa could therefore, be better in terms of increased commercial transactions as under 18 s could use it to make purchases.

${ }^{39}$ According to the International Monetary Fund the average cost for sending $\$ 200$ was between $\$ 15$ and \$26. Reported by the BBC 12/02/2006 'Mobile Phones to send Money Home' available at http://news.bbc.co.uk/1/hi/business/6353797.stm

${ }^{40}$ Ibid.

${ }^{41}$ As stated in the Vodafone Group Corporate Responsibility page of their website 21/03/2006 available at www.vodafone.co.uk

${ }^{42}$ Unfortunately the evidence so far from the limited availability of mobile financial services provided by UK banks indicates higher prices.

${ }^{43}$ For an analysis of how mobile phone technology can close the digital divide see 'Closing the Digital Divide: Who will invest in universal access', Stuart Weinstein and Charles Wild, Hertfordshire Law Journal Volume 4(1) pages $2-11$.

${ }^{44}$ As mentioned in section 1.

${ }^{45}$ Section 7, Annex: DOI Indicators.

46 'The Consumer Experience: Telecoms, Internet and Digital Broadcasting', 16/11/2006 available at www.ofcom.org.uk/research/tce/tidb/

${ }^{47}$ However, the one key difference between the two is the fact that one of the stated basic transactions of M-pesa is the disbursement and repayment of loans. This may take an operator out of the electronic money regulations and into the sphere of normal banks. The Kenyan Central Bank has held that as Safaricom is not a financial organisation they do not need a banking licence. For a discussion on the legal nature of electronic money and the regulatory regime, it is recommended the reader reads Kohlbach, 'Making sense of Electronic Money', 2004 (1) The Journal of Information, Law and Technology (JILT). Available at http://elj.warwick.ac.uk/jilt/04-1/kohlbach.html

${ }^{48}$ Particularly in light of Greek Vodafone phone tapping scandal. Reported in the Financial Times $15 / 12 / 2006$.

${ }^{49}$ Commission Staff Working Document, Communication from the Commission to the Council, the European Parliament, the European Economic and Social Committee and the Committee of the Regions on the Review of the Regulatory Framework for electronic communications networks and services SEC (2006) 816.

${ }^{50}$ E-privacy Directive Art. 4(2).

51 'Hackers will target mobile banking, study warns', reported by John Blau, 23/01/2007 available at www.techworld.com/security/news/index.cfm?newsID=7828\&pagtype=all

${ }^{52}$ Reported in the Guardian by Richard Wray 'HSBC rings in mobile banking' 04/10/2006. 